\title{
RESEARCH
}

Open Access

\section{Responsiveness of health care services towards the elderly in Tanzania: does health insurance make a difference? A cross-sectional study}

Paul Joseph Amani ${ }^{1,2^{*}}$ (D) Malale Tungu ${ }^{2,3}$, Anna-Karin Hurtig ${ }^{2}$, Angwara Denis Kiwara ${ }^{3}$, Gasto Frumence ${ }^{3}$ and Miguel San Sebastián ${ }^{2}$

\begin{abstract}
Background: Responsiveness has become an important health system performance indicator in evaluating the ability of health care systems to meet patients' expectations. However, its measurement in sub-Saharan Africa remains scarce. This study aimed to assess the responsiveness of the health care services among the insured and non-insured elderly in Tanzania and to explore the association of health insurance $(\mathrm{HI})$ with responsiveness in this population.
\end{abstract}

Methods: A community-based cross-sectional study was conducted in 2017 where a pre-tested household survey, administered to the elderly $(60+$ years) living in Igunga and Nzega districts, was applied. Participants with and without health insurance who attended outpatient and inpatient health care services in the past three and 12 months were selected. Responsiveness was measured based on the short version of the World Health Organization (WHO) multi-country responsiveness survey study, which included the dimensions of quality of basic amenities, choice, confidentiality, autonomy, communication and prompt attention. Quantile regression was used to assess the specific association of the responsiveness index with health insurance adjusted for sociodemographic factors.

Results: A total of 1453 and 744 elderly, of whom 50.1 and 63\% had health insurance, used outpatient and inpatient health services, respectively. All domains were rated relatively highly but the uninsured elderly reported better responsiveness in all domains of outpatient and inpatient care. Waiting time was the dimension that performed worst. Possession of health insurance was negatively associated with responsiveness in outpatient $(-1$; $95 \% \mathrm{Cl}:-1.45,-0.45)$ and inpatient $(-2 ; 95 \% \mathrm{Cl}:-2.69,-1.30)$ care.

Conclusion: The uninsured elderly reported better responsiveness than the insured elderly in both outpatient and inpatient care. Special attention should be paid to those dimensions, like waiting time, which ranked poorly. Further research is necessary to reveal the reasons for the lower responsiveness noted among insured elderly. A continuous monitoring of health care system responsiveness is recommended.

Keywords: Health insurance, Responsiveness, Elderly, Tanzania

\footnotetext{
* Correspondence: amani.paul@gmail.com

'Department of Health Systems Management, School of Public

Administration and Management, Mzumbe University, Morogoro, Tanzania

Epidemiology and Global Health, Umeå International School of Public

Health, Umeå University, Umeå, Sweden

Full list of author information is available at the end of the article
}

(c) The Author(s). 2020 Open Access This article is licensed under a Creative Commons Attribution 4.0 International License, which permits use, sharing, adaptation, distribution and reproduction in any medium or format, as long as you give appropriate credit to the original author(s) and the source, provide a link to the Creative Commons licence, and indicate if changes were made. The images or other third party material in this article are included in the article's Creative Commons licence, unless indicated otherwise in a credit line to the material. If material is not included in the article's Creative Commons licence and your intended use is not permitted by statutory regulation or exceeds the permitted use, you will need to obtain permission directly from the copyright holder. To view a copy of this licence, visit http://creativecommons.org/licenses/by/4.0/. The Creative Commons Public Domain Dedication waiver (http://creativecommons.org/publicdomain/zero/1.0/) applies to the data made available in this article, unless otherwise stated in a credit line to the data. 


\section{Background}

In low and middle-income countries (LMIC), health care systems are likely to be challenged by the rapidly increasing numbers of the elderly population [1-5]. A large proportion of this group are socio-economically disadvantaged and live in rural areas with poor health care infrastructure [6,7]. Compounding this situation is the increasing need for health care services adapted to non-communicable diseases like diabetes, hypertension, a variety of cancers and deteriorating physical mobility, which predominantly affect the elderly [8, 9]. Many LMICs have initiated reforms to their health care systems with a focus on improving the availability and accessibility of health care services for this vulnerable population group. These reforms are in line with the World Health Organization's (WHO) proclamation concerning universal health coverage (UHC), which focuses on building an enabling health system that is able to provide equitable health care access and financial protection to people, regardless of their capacity to pay [10]. This milestone requires a political commitment and acceptability, particularly in sub-Saharan countries, where health systems are generally weak [4].

When countries decide to reform their health care systems, monitoring and evaluation become an inescapable strategy for ensuring good performance [11]. In 2000, the WHO emphasised the need to put mechanisms in place to ensure the health system's ability to improve the health of the population, to protect the poor from potential care expenditures and to respond to legitimate expectations of people, thereby increasing the degree of responsiveness [12].

The concept of responsiveness was therefore introduced to capture patients' experience with the health system based on a common set of non-health domains [11-15]. These include the quality of basic amenities, choice, confidentiality, autonomy, communication and prompt attention. As they are developed from an extensive array of disciplines, responsiveness domains analyse the function of the health care system from the way patients experience care, the treatment procedures and the environment around the services [16-18]. Although responsiveness has increasingly been promoted as a key goal of any health system, its measurement remains scarce $[11,12,17,19,20]$. Studies on responsiveness have been more common in high-income countries $[14,21-23]$ than in LMICs $[17,24]$. In the former, health care users have mainly reported concerns regarding trust, long waiting times, lack of empathy and friendliness, and limited involvement in decisionmaking $[22,23,25]$. In the case of the LMICs, different studies $[9,13,15,20]$ have shown choice of service provider, autonomy, prompt attention, quality of basic amenities and confidentiality as important areas of concern in terms of responsiveness. In sub-Saharan
Africa, studies from Nigeria [11] and South Africa [26] have also shown the usefulness of the responsiveness domains in examining the operationalisation of health systems in the context of health insurance schemes. These studies identified the domains of access, autonomy, communication and prompt attention as important areas that the management of health insurance (HI) should work on in order to improve the responsiveness noted among the insured.

Towards the end of the 1980s, Tanzania, like other LMICs, was compelled to improve its health care system through attempts to minimise budgetary constraints [27]. These improvements consisted of the introduction of $\mathrm{HI}$ to the country as part of the primary health care strategy.

Community Health Fund (CHF) was piloted in the Igunga district in 1996 and was later introduced in other districts across the country as a voluntary scheme for rural households and their dependents, who agreed to contribute the same amount of premium. Although $\mathrm{Na}$ tional Health Insurance Fund (NHIF) was originally introduced in 2001 as a mandatory scheme to cover public servants, currently its coverage has been extended to the informal sector as well. Both schemes strive to improve access and utilisation of basic health care services by the poor and the vulnerable population, including the elderly, with the goal of achieving UHC [28-30]. Research has shown that $\mathrm{HI}$ can contribute to improving the health care system's ability to deliver health services, particularly among low socio-economic groups [11, 31]. However, little is known about how HI contributes to the responsiveness of health care services. To our knowledge, only one recent study has addressed the issue of responsiveness of primary health care services in Tanzania [32], but none has focused on the role of $\mathrm{HI}$ or elderly care.

Thus, this study aimed to assess the responsiveness of the health care services among the insured and noninsured elderly in Tanzania and to explore the association of $\mathrm{HI}$ with responsiveness in this population, in order to contribute with relevant knowledge to improve the performance of the health care system for the elderly in the country.

\section{Methods \\ Study setting}

The study was conducted in Nzega and Igunga districts in the Tabora region, which is located in western-central Tanzania. According to the 2012 census, the region had 2.3 million inhabitants, of which 901,979 resided in Nzega and Igunga districts [33]. The number of people aged 60 years and above living in these districts was 50 , 547 , approximately $5 \%$ of the total population. We chose the two districts for logistical reasons, as the two are 
neighbours, both with a majority of the elderly residing in rural areas, and Igunga was the first district in the country to experience the CHF. In both districts, primary and secondary health facilities are available and offer health care services to the elderly regardless of their insurance status. While the retired elderly from the public sector who had already joined the NHIF are covered until their death, those who are not can voluntarily join the CHF. An insured elderly person is entitled to a broad range of free services, including outpatient consultation, prescriptions, surgical services, inpatient care services, physiotherapy and rehabilitation services, optical and dental health services $[28,34,35]$.

\section{Sample size and sampling procedures}

This study is part of a broader project assessing the role of $\mathrm{HI}$ among the rural elderly. A household-based survey of elderly people aged 60 years or more, living in Igunga and Nzega districts, was conducted between July and September 2017. A multistage sampling technique to select the wards and villages in each district was applied. First, through a convenient sampling technique, fourteen wards were selected randomly, seven from each district (around 1/5 of the total number of wards from each district) based on population size and logistics. Second, a total of 58 villages that were geographically reachable from the fourteen wards were randomly selected by using a lottery method. Third, hamlet officers helped us to identify and select 25 to 44 households with an elderly person from each village, depending on village size. Lastly, one respondent, either male or female, was randomly selected and interviewed from each household. The inclusion criteria for respondents were: to be aged 60 years or over; currently living in the selected districts; and visiting an outpatient or inpatient service in the last three or 12 months. Given the lack of studies on responsiveness in Tanzania and the variety of results found in the literature, we based our outcome prevalence on one of the studies with the lowest overall responsiveness score [13]. Based on a $40 \%$ prevalence of good responsiveness in outpatient care, a design effect of two, a 95\% confidence interval and power of $80 \%, 733$ participants were determined to form the sample size. This sample was used to obtain a representative group of males and females separately.

\section{Data collection}

A pre-tested household survey was first applied to understand the perception of the insured and uninsured elderly with regard to outpatient and inpatient health care services received in the past three and 12 months, respectively. We employed eight data collectors who were fluent in the Swahili and Sukuma languages and had at least a bachelor's degree in social sciences. Before starting data collection, the research assistants received training and became accustomed to the questions in order to reduce misunderstandings of the domain terms by themselves or the respondents.

\section{Defining the variables}

The responsiveness questions were based on the short version of the WHO multi-country survey study [14]. The responsiveness domains were measured by using the five ordered Likert scale options: $1=$ very good, $2=$ good, $3=$ moderate, $4=$ bad and $5=$ very bad. The general question addressing the six domains was: 'For your most recent visit to a health care provider/overnight stay, how would you rate the following: i) cleanliness of the facility's inside environment; ii) freedom to choose health care provider; iii) freedom to talk privately to the provider; iv) involvement in deciding treatment; v) clarity of explanation by providers, and vi) time waited before being attended'. Cronbach's alpha was used to measure the reliability of the instrument, which ranged, depending on the domain, between $0.68-0.89$, which can be considered as acceptable.

Health insurance status was determined with a 'Yes/ No' question by asking the elderly if they possessed HI (public or private). The elderly were requested to show their HI membership cards (all did), as well as to state the date they joined the scheme.

The sociodemographic factors included were: i) sex/ gender, identified as male or female; ii) age, categorised as between 60 and $69,70-79$ and $>79$ years old; iii) marital status was divided into: married (currently married and cohabiting) and other (widows, separated and never married); iv) education was categorised as none, low education - those with a primary education or less - and high education, those with a secondary education or higher; and v) income was determined by asking about the total income of the individual elderly and categorised as less or equal to $\$ 22.50$ and above $\$ 22.50$. The cut-off is based on the Tanzanian 2011-2012 basic need poverty line estimates, which stood at $236,482 \mathrm{Tsh}$ (approximate to $\$ 22.5$ ) per adult per month in 2018 .

\section{Ethical clearance}

The Research and Ethics Committee of Muhimbili University of Health Sciences reviewed and approved the study protocol in May 2017 (reference number 2017-0524/AEC/Vol.XII/70). Permission to conduct data collection from the District Executive Directors of Igunga and Nzega districts was obtained. Then, an informed written consent was obtained from participants and verbal consent was obtained from those who could not read and write, after the local guide had introduced the research assistant and the procedures for research in each 
household including their rights to participate or withdraw from the study.

\section{Data analysis}

The data were entered into Epi Info and analysed with STATA version 15. First, a descriptive analysis presenting the characteristics of the study sample was carried out. Then, the degree of responsiveness by type of care based on the five categories of responses $(1=$ very good to $5=$ very bad $)$ was analysed. To obtain a responsiveness index, the scores for each domain were first reverse coded to $5=$ very good and $1=$ very bad and then added, resulting in an index ranging from six, indicating the lowest, to 30 , the highest score [2]. Chi-square tests were applied to compare the health systems' responsiveness domains according to the possession or not of HI. Since a non-normal distribution of the index was observed, a median quantile regression (50th percentile) was used to explore the specific association of the responsiveness index with HI ownership and sociodemographic factors. Statistically significant variables ( $p$-value < 0.05 ) in the crude model were included in the adjusted model.

Table 1 Characteristics of respondents by use of health care services

\begin{tabular}{|c|c|c|}
\hline Characteristics & $\begin{array}{l}\text { Outpatient } \\
(n=1453)\end{array}$ & $\begin{array}{l}\text { Inpatient } \\
(n=744)\end{array}$ \\
\hline \multicolumn{3}{|l|}{ Gender } \\
\hline Male & 704 (48.45\%) & 349 (46.91\%) \\
\hline Female & 749 (51.55\%) & 395 (53.09\%) \\
\hline \multicolumn{3}{|l|}{ Age (years) } \\
\hline $60-69$ & 849 (58.43\%) & 424 (56.99\%) \\
\hline $70-79$ & $378(26.12 \%)$ & 189 (25.40\%) \\
\hline$>79$ & $226(15.55 \%)$ & $131(17.61 \%)$ \\
\hline \multicolumn{3}{|l|}{ Marital status } \\
\hline Married & $640(44.05 \%)$ & $344(46.24 \%)$ \\
\hline Other & 813 (55.95\%) & $400(53.76 \%)$ \\
\hline \multicolumn{3}{|l|}{ Education } \\
\hline None & 828 (56.99\%) & $425(57.12 \%)$ \\
\hline Low & 563 (38.74\%) & 289 (38.84\%) \\
\hline High & 62 (4.27\%) & $30(4.04 \%)$ \\
\hline \multicolumn{3}{|l|}{ Income } \\
\hline$\leq 22.50 \$$ & 970 (66.75\%) & $504(67.74 \%)$ \\
\hline$>22.50 \$$ & 483 (33.24\%) & $240(32.26 \%)$ \\
\hline \multicolumn{3}{|c|}{ Health insurance } \\
\hline No & $722(49.69 \%)$ & 275 (36.96\%) \\
\hline Yes & 731 (50.31\%) & 469 (63.04\%) \\
\hline
\end{tabular}

\section{Results}

Characteristics of the respondents

Table 1 portrays the descriptive characteristics of the elderly people who were involved in this study. The final sample included 1453 and 744 elderly people who reported using outpatient and inpatient services in the last three and 12 months, respectively. A similar distribution of respondents between outpatient and inpatient care was observed for the different sociodemographic variables. Study participants were mostly younger (60-65 years), not currently married, with no education and low income. While half of the respondents in the outpatient group were insured, the coverage increased to $63 \%$ in the inpatient group.

\section{Performance of the responsiveness domains by health insurance}

Through ratings, the experience of the elderly regarding the six responsiveness domains based on their insurance status was explored. In general, good (including very good, good and moderate) responsiveness was reported in all domains for outpatient care except waiting time. The uninsured elderly reported better responsiveness than the insured in all domains of outpatient care including cleanliness of the facility, involvement in treatment decisions and waiting time which were statistically significant (Fig. 1a and b).

Similar to outpatient care, the uninsured elderly reported better responsiveness than the insured in all domains of inpatient care. The same dimensions as in outpatient care, cleanliness, making decisions and waiting time performed statistically lower among the insured compared to the uninsured (Fig. 2a and b).

\section{Regression analysis}

Table 2 shows the results of the crude and adjusted regressions of the median quantile analyses estimating the association between $\mathrm{HI}$ and both the outpatient and inpatient overall responsiveness index, adjusted for sociodemographic variables.

\section{Outpatient care}

Results of the crude and adjusted regression models showed a negative statistical association between $\mathrm{HI}$ and responsiveness regarding outpatient care. The responsiveness perceived by the insured elderly was one unit less $(-1$; $95 \% \mathrm{CI}$ : $-1.45,-0.45)$ than that of the uninsured elderly. In addition, a negative statistical association between age, gender and marital status with responsiveness was observed. The increase in age decreased the probability of reporting better responsiveness by one unit $(-1 ; 95 \% \mathrm{CI}:-1.70,-0.29)$ among the group aged 70 to 79 years and two units $(-2$; 95\% CI: $2.85,-1.14)$ in the group aged 79 years or older, as well 


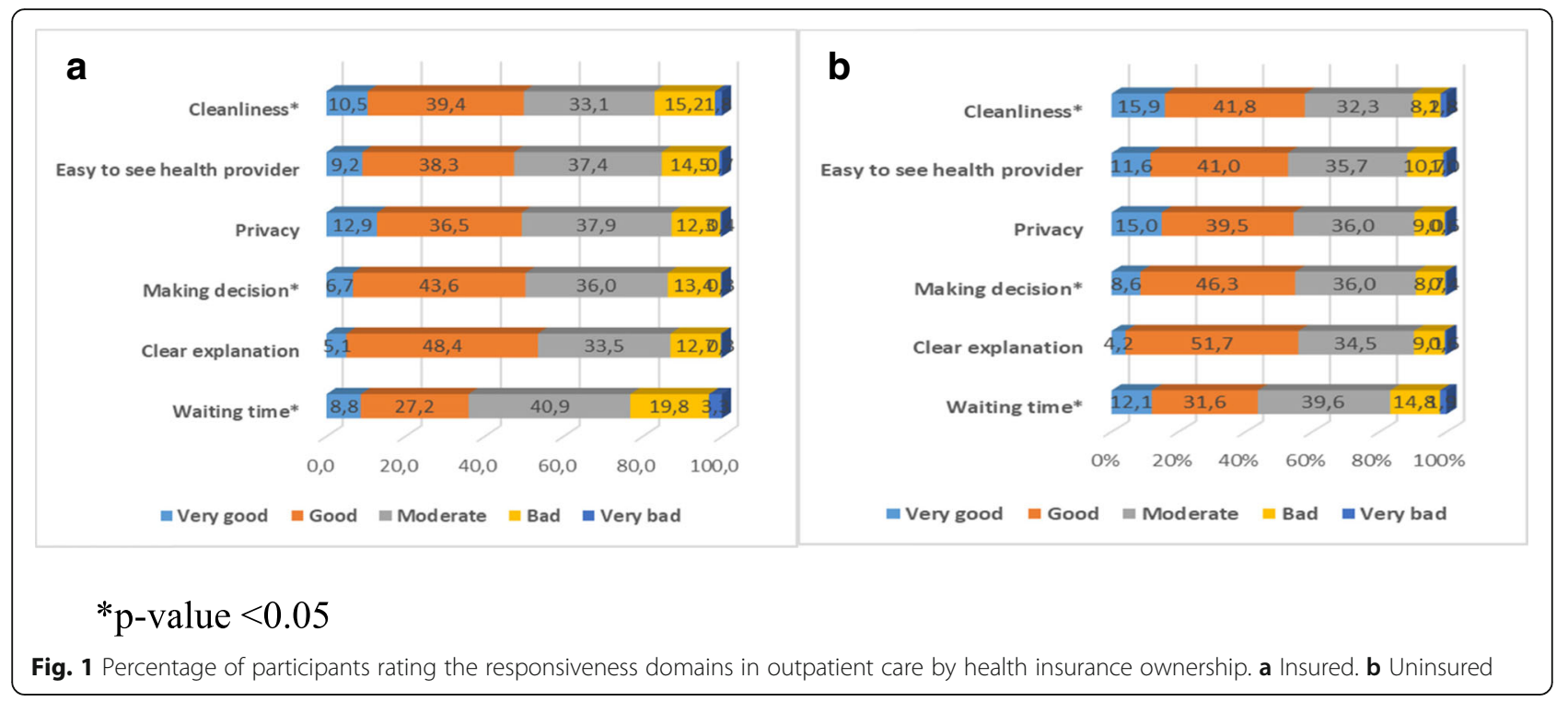

as among females and married people $(-1 ; 95 \% \mathrm{CI}-$ $1.60,-0.39)$, whereas high education $(+2$; $95 \%$ CI: 0.78 , $3.21)$ and high income $(+1$; $95 \%$ CI: $0.36,1.63)$ were associated with higher responsiveness.

\section{Inpatient care}

The results of the crude models also showed a negative association between $\mathrm{HI}$ and responsiveness in relation to inpatient care $(-2 ; 95 \%$ CI: $-2.69,-1.30)$. No adjusted models were conducted, since none of the sociodemographic variables (age, gender, marital status education and income) showed a significant association with responsiveness to inpatient care in the bivariate regression.

\section{Discussion}

To our knowledge, this is the first study analysing the responsiveness of health care services in Tanzania by insurance status. In this section, we first discuss the performance of the different domains and then the difference in responsiveness perceived by the insured and the uninsured elderly.

\section{Responsiveness in outpatient and inpatient care}

Based on our findings, both the insured and uninsured elderly reported good responsiveness (very good/good/ moderate $250 \%$ ) in all domains of outpatient and inpatient care. High scores in all domains were also found in the Tanzanian study that explored responsiveness in primary health care among the general population [32]. In our study, the perceived health care responsiveness was, however, lower among the insured compared to the uninsured elderly in all domains of both types of care. Our results are in line with the findings of similar studies from sub-Saharan Africa. In a study conducted in

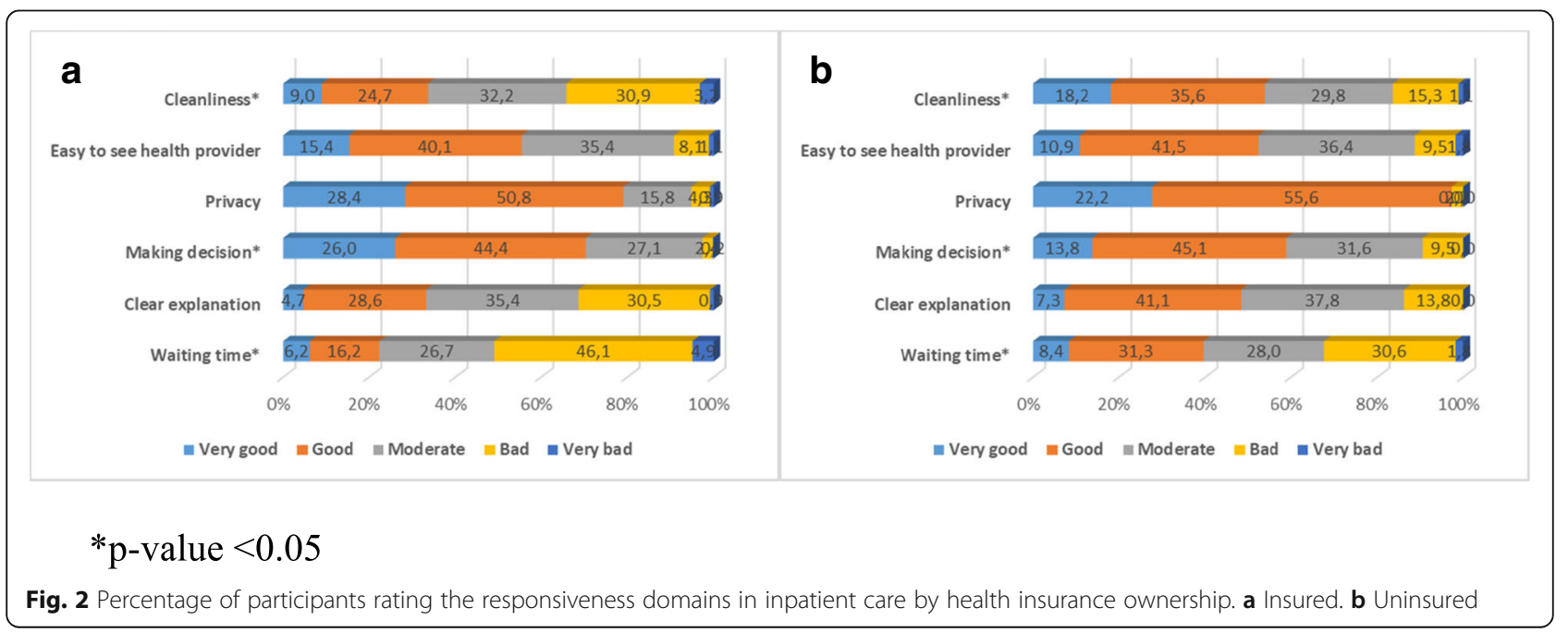


Table 2 Results of crude and adjusted median quantile regression models for responsiveness to health care services

\begin{tabular}{|c|c|c|c|}
\hline \multirow[b]{2}{*}{ Characteristics } & \multicolumn{2}{|c|}{ Outpatient $(n=1453)$} & \multirow{2}{*}{$\begin{array}{l}\text { Inpatient }(n=744) \\
\text { Crude model }\end{array}$} \\
\hline & Crude model & Adjusted model & \\
\hline \multicolumn{4}{|l|}{ HI } \\
\hline No & Reference category & & \\
\hline Yes & $-0.7(-1.17,-0.32)$ & $-1(-1.45,-0.45)^{*}$ & $-1.8(-2.36,-1.24)^{*}$ \\
\hline \multicolumn{4}{|l|}{ Age (years) } \\
\hline $60-69$ & Reference category & & \\
\hline $70-79$ & $-0.6(-1.10,-0.10)$ & $-1(-1.70,-0.29)^{*}$ & $-0.5(-1.15,0.17)$ \\
\hline$>79$ & $-1(-1.65,-0.44)$ & $-2(-2.85,-1.14)^{*}$ & $0.3(-0.44,1.06)$ \\
\hline \multicolumn{4}{|l|}{ Gender } \\
\hline Male & Reference category & & \\
\hline Female & $-0.7(-1.12,-0.27)$ & $-1(-1.60,-0.39)^{*}$ & $-0.1(-0.63,0.48)$ \\
\hline \multicolumn{4}{|l|}{ Marital status } \\
\hline Other & Reference category & & \\
\hline Married & $-0.4(-0.87,-0.02)$ & $-1(-1.60,-0.39)^{*}$ & $-0.0(-0.57,0.54)$ \\
\hline \multicolumn{4}{|l|}{ Education } \\
\hline None & Reference category & & \\
\hline Low & $0.2(-0.12,0.70)$ & $1(0.49,1.50)^{*}$ & $0.2(-0.30,0.84)$ \\
\hline High & $1(0.17,2.30)$ & $2(0.78,3.21)^{*}$ & $1.3(-0.30,2.70)$ \\
\hline \multicolumn{4}{|l|}{ Income } \\
\hline$<22 \$$ & Reference category & & \\
\hline$>22 \$$ & $0 .(-0.38,0.51)$ & & $0.3(-0.34,0.84)$ \\
\hline
\end{tabular}

South Africa among insured and uninsured older adults ( 50 years and above), a good health system responsiveness was observed in all domains of outpatient and inpatient care [15]. Similar experiences have been reported by insured and uninsured patients in Nigeria, who indicated a high responsiveness in outpatient care [11].

Three domains - access (ease of seeing a health provider), confidentiality (privacy) and autonomy (involvement in decision-making) - performed better among both the insured and uninsured elderly in outpatient and inpatient care services. This finding differs from the results of the previous South African study [15], which reported patient dissatisfaction with the access and autonomy domains of the health care system. The observed better responsiveness concerning access shown in our study may be a result of the government's ongoing efforts to improve service delivery, particularly at the primary health care level, which is widely available in rural areas. According to Röttger et al. [23], users of health care services expect a high level of privacy and assurance that whatever personal information they discuss with health care providers is safeguarded. In our study, the confidentiality domain performed satisfactorily, similar to the South African study [15] that reported high responsiveness $(74.2 \%)$ in that domain. However, in our study setting, many health facilities were small, had limited space for patient-doctor meetings and used the available space for multiple activities. It could be that elderly patients were comfortable with the level of confidentiality because it had recently improved, and/or they did not have other experience to compare. Nevertheless, there is a need to readjust the facility's space and remind health care providers of the ethics of information privacy. Autonomy describes the rights of a patient to medical information and to make informed choices [11]. Involving the elderly in making decisions about their health may enhance patient-doctor relationships, which are important in the care process [25]. Although information asymmetry is common in health care settings, the findings from our study appear to highlight an existing good relationship between health care providers and patients in the sense that it gives the patient a sense of control and responsibility and hence, allows them to be involved in the care activity [36].

Our results revealed a concern by the elderly regarding three responsiveness domains: prompt attention (waiting time), quality of basic amenities (cleanliness) and communication (clear explanations). These findings are similar to previous studies on health care responsiveness among older adults in South Africa [15], China [13] and 
Nigeria [11]. Nevertheless, our scores regarding prompt attention were extremely low (18.15\% in outpatient and $21.85 \%$ in inpatient care) compared to those of South Africa (58.2\% for outpatient and $68.6 \%$ for inpatient) and Nigeria (68\% for outpatient care). In line with other research, dissatisfaction of the elderly may be associated with overcrowding, understaffing, limited geriatric skills, delays in reception, unavailability of recommended medicine, attitude of providers towards the elderly and processing insurance claims $[11,37,38]$. Similar to prompt attention, neither insured nor uninsured patients were satisfied with the cleanliness of the facilities. These findings are different from other studies $[26,37]$ in which this domain was scored highly and deemed important. In our study, cleanliness was perceived as poor (21.35\%) for inpatient care compared to the South African study, which was $71.3 \%$ [26]. There is definitely a need for health care managers to improve the cleanliness of their facilities in order to offer a quality service. In line with the WHO [12], communication is also very important in improving the delivery and utilisation of health care. However, the dissatisfaction observed with communication in this study may imply that providers do not take enough time to listen to and understand the problems of elderly patients. This is a not a good practice, as it disempowers the service users, makes them feel uncomfortable with the provider and may lead to decreased trust in the health care delivery system.

\section{Factors associated with responsiveness}

The elderly with HI reported worse responsiveness compared to the uninsured, in the adjusted quantile regression models. This finding can appear to be contradictory at first sight. Although research from Ghana has shown similar results [39], in which insured patients tended to perceive worse quality of health care, a study from Burkina Faso [40] showed no difference in the quality of health care among insured and uninsured patients. Two main reasons could be argued for the difference in our study: difference in procedures when visiting a health facility and unfulfilled expectations. In the Tanzanian health care setting, an insured elderly person has to go through a long process before being seen by a doctor. They start by submitting the insurance card at the reception and then wait while undergoing verification through the computer system, which may take a long time due to overcrowding. However, the uninsured pay cash and get the services immediately, which is a quicker process with commonly shorter queues than that of the insured patients. Furthermore, the fact that patients are given appointments for a particular day but not time, and may not be seen immediately due to the 'first comefirst-served' modality, added to the overcrowding of health facilities particularly in the insured section, can contribute to this finding [37]. A similar experience from Ghana showed that dissatisfaction of the insured was associated with long waiting times, inadequate information regarding services, poor staff attitudes, non-observance of the queuing process and perceived low quality of drugs [39]. Related to the second explanation, insured patients may expect to be attended by professionals who show concern for and understanding of their health problems, to experience shorter waiting times and to receive better quality services than the uninsured. If this does not happen, responsiveness can be perceived as being worse.

Among the independent variables, older age, female and being married showed a negative statistically significant association to responsiveness in outpatient care. The result regarding age is, however, opposite to other studies $[9,15]$ that have reported more responsiveness by older people. One possible explanation might be that health care services are used more often with age, making elderly more negative towards them. Literature offers different findings regarding gender and responsiveness. In the South African study, female inpatients indicated higher health care responsiveness [15], whereas in studies from Ethiopia [41] and Ghana [9], gender differences did not influence the responsiveness perception among older patients. This difference might require further exploration. Higher educational attainment tended to be positively associated with perceived responsiveness in outpatient and inpatient care. This finding is similar to other studies [42-44] which showed increased responsiveness with higher education, but it differs from the findings of a study in Ethiopia [45]. A probable explanation might be that elderly people with higher education have a better knowledge of what services they need, as well as greater ability to interact with the providers and navigate within the system [19].

\section{Methodological considerations}

The survey used to explore the responsiveness of health care services was based on the responsiveness questions included in the WHO multi-country responsiveness survey study [14], which allowed for consistency and comparison with other studies. The response rate was high (above 80\%), probably due to the recruitment of research assistants who were fluent in the local language and the culture of the study respondents. The fact that our sample size was relatively high, with both males and females represented, increases the internal validity of our findings. However, generalisation of the results to other parts of the country should be undertaken cautiously. Several measures were taken to minimise the possibilities of bias and misinterpretation by both the interviewers and the respondents. In order to reduce interviewer misinterpretation and thus respondent bias, 
we conducted a pilot test of the instrument, with thorough training for the research assistants. The responsiveness questions related to health care utilisation might have created recall bias. This was partly dealt with by requesting to see $\mathrm{HI}$ cards and hospital registration numbers for a randomly selected number of respondents during interviews. Selection bias was partly taken into consideration because of the randomisation process of the participants' selection. Finally, we could not distinguish to which kind of $\mathrm{HI}$ participants belonged, which could have influenced the perception of the responsiveness domains.

\section{Conclusion}

To our knowledge, this is the first study analysing the responsiveness of the health care services in Tanzania with a focus on insurance status among the elderly. The uninsured elderly reported better responsiveness in all domains than the insured, and a negative association between $\mathrm{HI}$ and the responsiveness index in outpatient and inpatient care was observed. The results suggest that further attention to the HI procedure is needed in order to further improve the responsiveness of the health care services. For service providers, the results highlight the importance of considering needs, values and preferences of elderly patients to improve their experience and perceptions as well as to meet their expectations of the health care provided. Policymakers would need to take measures in order to improve three main aspects of care - communication between doctors and patients, prompt attention and cleanliness - to meet the expectations of elderly patients. The government of Tanzania is planning to improve in the nearest future access and to ensure UHC for all people. It would be worth undertaking careful monitoring of the process of implementation of these strategies from a responsiveness perspective.

\section{Acknowledgements}

We are grateful to the financial support from SIDA and the support of the District Executive Directors, Ward Executive Officers, village and hamlet leaders, research assistants the elderly respondents from Nzega and Igunga Disticts in Tanzania.

\section{Authors' contributions}

PJA conceived the study. PJA and MT participated in its design, collected data, analysed data and drafted the manuscript. ADK participated in the design, was the overall coordinator of the project and helped to draft the manuscript. GF, AKH and MSS participated in the design, analysis and helped to draft the manuscript. The authors read and approved the manuscript.

\section{Funding}

This study funded by SIDA through MUHAS-UMEA Universities under the Health System Research Subprogram 2015-2020.

\section{Availability of data and materials}

Not available.

\section{Ethics approval and consent to participate}

The Research and Ethics Committee of Muhimbili University of Health and Allied Sciences (MUHAS) reviewed and approved the study protocol in May
2017 (reference number 2017-05-24/AECNol.XII/70). The District Executive Directors of Igunga and Nzega districts granted permission to conduct data collection. Then, an informed written consent was obtained from the participants and verbal consent was obtained from those who could not read and write after the local guide had introduced the research assistant and the procedures for research in each household including their rights to participate or withdraw from the study.

\section{Consent for publication}

The ethical approval provides the consent for publication.

\section{Competing interests}

The authors declare that they have no competing interest in this study.

\section{Author details}

${ }^{1}$ Department of Health Systems Management, School of Public

Administration and Management, Mzumbe University, Morogoro, Tanzania.

${ }^{2}$ Epidemiology and Global Health, Umeå International School of Public Health, Umeå University, Umeå, Sweden. ${ }^{3}$ Department of Development Studies, School of Public Health and Social Sciences, Muhimbili University of Health and Allied Sciences, Dar es Salaam, Tanzania.

Received: 18 March 2020 Accepted: 25 August 2020

Published online: 12 October 2020

\section{References}

1. Myburgh NG, Solanki GC, Smith MJ, Lalloo R. Patient satisfaction with health care providers in South Africa: the influences of race and socioeconomic status. International J Qual Health Care. 2005;17(6):473-7. https://doi.org/10. 1093/intqhc/mzi062.

2. Saeed BI, Xicang Z, Yawson AE, Nguah SB, Nsowah-Nuamah NN. Impact of socioeconomic status and medical conditions on health and healthcare utilization among aging Ghanaians. BMC Public Health. 2015;15(1):276. https://doi.org/10.1186/s12889-015-1603-y.

3. Maeder AJ, Ho K, Marcelo A. The promise of new technologies in an age of new health challenges: selected papers from global Telehealth, vol. 231. New Zealand: IOS Press; 2016.

4. Harries AD, Jensen PM, Zachariah R, Rusen ID, Enarson DA. How health systems in sub-Saharan Africa can benefit from tuberculosis and other infectious disease programmes [unresolved issues]. Int J Tuberc Lung Dis. 2009;13(10):1194-9 http://hdl.handle.net/10144/85113.

5. Adini B. Ethnic inequality within the elderly population in utilizing healthcare services. Isr J Health Policy Res. 2019;8(1):39. https://doi.org/10. 1186/s13584-019-0311-y.

6. Hutton D. Older persons in emergencies: considerations for action and policy development. Geneva: World Health Organization; 2008.

7. Van Der Wielen N, Channon AA, Falkingham J. Does insurance enrolment increase healthcare utilisation among rural-dwelling older adults? Evidence from the National Health Insurance Scheme in Ghana. BMJ Glob Health. 2018;3(1). https://doi.org/10.1136/bmjgh-2017-000590.

8. World Health Organization. World report on ageing and health. Geneva: World Health Organization; 2015. Available at https://www.who.int/ageing/ publications/world-report-2015/en/ Accessed on 27th June 2019.

9. Awoke MA, Negin J, et al. Predictors of public and private healthcare utilization and associated health system responsiveness among older adults in Ghana. Glob Health Action. 2017;10(1):1301723. https://doi.org/10.1080/ 16549716.2017.1301723.

10. World Health Organization. World health report: health system financing-the path to universal coverage. Geneva: World Health Organization; 2010.

11. Mohammed S, Bermejo JL, Souares A, Sauerborn R, Dong H. Assessing responsiveness of health care services within a health insurance scheme in Nigeria: users' perspectives. BMC Health Serv Res. 2013;13(1):502. https://doi. org/10.1186/1472-6963-13-502.

12. World Health Organization. The world health report: 2000: health systems: improving performance. Geneva: World Health Organization; 2000. Available at http://www.who.int/whr/2000/en/whr00_en.pdf. Accessed on 27 June 2019.

13. Kowal P, Naidoo N, Williams SR, Chatterji S. Performance of the health system in China and Asia as measured by responsiveness. Health. 2011; 3(10):638. https://doi.org/10.4236/health.2011.310108.

14. Valentine NB, Bonsel GJ, Murray CJ. Measuring quality of health care from the user's perspective in 41 countries: psychometric properties of WHO's 
questions on health systems responsiveness. Qual Life Res. 2007;16(7):110725. https://doi.org/10.1007/s11136-007-9189-1.

15. Peltzer K, Phaswana-Mafuya N. Patient experiences and health system responsiveness among older adults in South Africa. Glob Health Action. 2012;5(1):18545. https://doi.org/10.3402/gha.v5i0.18545.

16. De Silva A, Valentine N. A framework for measuring responsiveness. Geneva: World Health Organization; 2000. https://apps.who.int/iris/bitstream/ handle/10665/67781/a78638.pdf. Accessed on 25 June 2019.

17. Mirzoev T, Kane S. What is health systems responsiveness? Review of existing knowledge and proposed conceptual framework. BMJ Glob Health. 2017;2(4):e000486. https://doi.org/10.1136/bmjgh-2017-000486.

18. Coulter A, Jenkinson C. European patients' views on the responsiveness of health systems and healthcare providers. Eur J Public Health. 2005;15(4): 355-60. https://doi.org/10.1093/eurpub/cki004.

19. Robone S, Rice N, Smith PC. Health systems' responsiveness and its characteristics: a cross-country comparative analysis. Health Serv Res. 2011; 46(6pt2):2079-100. https://doi.org/10.1111/j.1475-6773.2011.01291.x.

20. Dadgar E, Rashidian A, Majdzadeh R, Arab M, Kazemi-galougahi MH. Assessing trend of health system responsiveness in Iran using household survey (before and after the implementation of health transformation plan). Health Scope. 2018;7(S). https://doi.org/10.5812/jhealthscope.63866.

21. Murray CJ, Frenk J. Ranking 37th-measuring the performance of the US health care system. N Engl J Med. 2010;362(2):98-9. https://doi.org/10.1056/ NEJMp0910064

22. Murante AM, Seghieri $C$, Vainieri $M$, et al. Patient-perceived responsiveness of primary care systems across Europe and the relationship with the health expenditure and remuneration systems of primary care doctors. Soc Sci Med. 2017;186:139-47. https://doi.org/10.1016/j.socscimed.2017.06.005.

23. Röttger J, Blümel $M$, Engel $S$, et al. Exploring health system responsiveness in ambulatory care and disease management and its relation to other dimensions of health system performance (RAC)-study design and methodology. Int J Health Policy Manag. 2015;4(7):431. https://doi.org/10. 15171/IJHPM.2015.97.

24. Rashidian A, Kavosi Z, Majdzadeh R, et al. Assessing health system responsiveness: a household survey in 17th district of Tehran. Iran Red Crescent Med J. 2011;13(5):302.

25. Röttger J, Blümel M, Fuchs $S$, et al. Assessing the responsiveness of chronic disease care - is the World Health Organization's concept of health system responsiveness applicable? Soc Sci Med. 2014;113:87-94. https://doi.org/10. 1016/j.socscimed.2014.05.009.

26. Peltzer K. Patient experiences and health system responsiveness in South Africa. BMC Health Serv Res. 2009;9(1):117. https:/doi.org/10.1186/1472-6963-9-117.

27. Mujinja PG, Kida TM. Implications of health sector reforms in Tanzania: policies, indicators and accessibility to health services. Economic and Social Research Foundation; 2014. http://www.thdr.or.tz/docs/THDR-BP-8.pdf. Accessed on 15 Oct 2019.

28. Mtei G, Makawia S, Ally M, Kuwawenaruwa A, Meheus F, Borghi J. Who pays and who benefits from health care? An assessment of equity in health care financing and benefit distribution in Tanzania. Health Policy Plan. 2012; 27(suppl_1):i23-34. https://doi.org/10.1093/heapol/czs018.

29. Macha J, Harris B, et al. Factors influencing the burden of health care financing and the distribution of health care benefits in Ghana, Tanzania and South Africa. Health Policy Plan. 2012;27(suppl_1):i46-54. https://doi. org/10.1093/heapol/czs024

30. Macha J, Kuwawenaruwa A, Makawia S, Mtei G, Borghi J. Determinants of community health fund membership in Tanzania: a mixed methods analysis. BMC Health Serv Res. 2014;14(1):538. https://doi.org/10.1186/ s12913-014-0538-9.

31. Abuosi AA, Domfeh KA, Abor JY, Nketiah-Amponsah E. Health insurance and quality of care: comparing perceptions of quality between insured and uninsured patients in Ghana's hospitals. Int J Equity Health. 2016;15(1):76. https://doi.org/10.1186/s12939-016-0365-1.

32. Kapologwe NA, Kibusi SM, Borghi J, Gwajima DO, Kalolo A. Assessing health system responsiveness in primary health care facilities in Tanzania. BMC Health Serv Res. 2020;20(1):104. https://doi.org/10.1186/s12913-020-4961-9.

33. National Bureau of Statistics. 2012 population and housing census. Population distribution by administrative area; 2013. http://repository.out.ac. tz/362/. Accessed on 4 Apr 2019.

34. Kamuzora P, Gilson L. Factors influencing implementation of the community health Fund in Tanzania. Health Policy Plan. 2007:22(2):95-102. https://doi.org/10.1093/heapol/czm001.
35. Amu H, Dickson KS, Kumi-Kyereme A, Darteh EK. Understanding variations in health insurance coverage in Ghana, Kenya, Nigeria, and Tanzania: evidence from demographic and health surveys. PLoS One. 2018;13(8): e0201833. https://doi.org/10.1371/journal.pone.0201833.

36. Tutton EM. Patient participation on a ward for frail older people. J Adv Nurs. 2005;50(2):143-52. https://doi.org/10.1111/j.1365-2648.2005.03373.x.

37. Adesanya T, Gbolahan O, et al. Exploring the responsiveness of public and private hospitals in Lagos, Nigeria. J Public Health Res. 2012;1(1):2. https:// doi.org/10.4081/jphr.2012.e2.

38. Jehu-Appiah C, Aryeetey G, Agyepong I, Spaan E, Baltussen R. Household perceptions and their implications for enrolment in the National Health Insurance Scheme in Ghana. Health Policy Plan. 2011;27(3):222-33. https:// doi.org/10.1093/heapol/czr032.

39. Duku SK, Nketiah-Amponsah E, Janssens W, Pradhan M. Perceptions of healthcare quality in Ghana: does health insurance status matter? PLoS One. 2018;13(1):e0190911. https://doi.org/10.1371/journal.pone.0190911.

40. Robyn PJ, et al. Does enrollment status in community-based insurance lead to poorer quality of care?. Evidence from Burkina Faso. Int J Equity Health. 2013;12(1):31. https://doi.org/10.1186/1475-9276-12-31.

41. Woldeyohanes TR, Woldehaimanot TE, Kerie MW, et al. Perceived patient satisfaction with in-patient services at Jimma University specialized hospital, Southwest Ethiopia. BMC Res Notes. 2015;8(1):285. https://doi.org/10.1186/ s13104-015-1179-8.

42. Thi PL, Briancon S, Empereur F, Guillemin F. Factors determining inpatient satisfaction with care. Soc Sci Med. 2002;54(4):493-504. https://doi.org/10. 1016/S0277-9536(01)00045-4

43. Lee Y, Kasper JD. Assessment of medical care by elderly people: general satisfaction and physician quality. BMC Health Serv Res. 1998;32(6):741.

44. Kong MC, Camacho FT, Feldman SR, Anderson RT, Balkrishnan R. Correlates of patient satisfaction with physician visit: differences between elderly and non-elderly survey respondents. Health Qual Life Outcomes. 2007:5(1):62. https://doi.org/10.1016/S1098-3015(10)65337-5.

45. Assefa F, Mosse A. Assessment of clients' satisfaction with health service deliveries at Jimma University specialized hospital. Ethiop J Health Sci. 2011; 21(2):101-10. https://doi.org/10.4314/ejhs.v21i2.69050.

\section{Publisher's Note}

Springer Nature remains neutral with regard to jurisdictional claims in published maps and institutional affiliations.

\section{Ready to submit your research? Choose BMC and benefit from:}

- fast, convenient online submission

- thorough peer review by experienced researchers in your field

- rapid publication on acceptance

- support for research data, including large and complex data types

- gold Open Access which fosters wider collaboration and increased citations

- maximum visibility for your research: over $100 \mathrm{M}$ website views per year

At $\mathrm{BMC}$, research is always in progress.

Learn more biomedcentral.com/submissions 